\title{
Cardiac arrest from massive carbon dioxide embolism during endoscopic saphenous vein harvesting
}

\author{
Masashi Kawabori, MD, ${ }^{a}$ Conor Kinford, BA, ${ }^{\mathrm{b}}$ Jamel Ortoleva, MD, ${ }^{\mathrm{c}}$ and Gregory S. Couper, MD, ${ }^{\mathrm{a}}$ \\ Boston, Mass
}

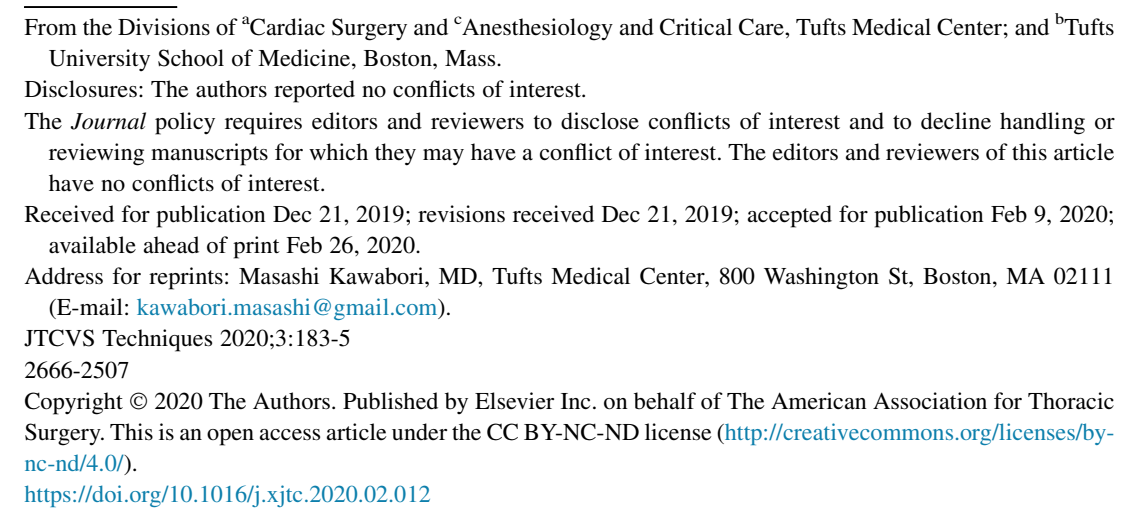

Video clip is available online.

Endoscopic saphenous vein harvesting (EVH) is a safe, welladopted standard minimally invasive vein harvesting procedure for coronary artery bypass grafting $(\mathrm{CABG})$ surgery that requires carbon dioxide $\left(\mathrm{CO}_{2}\right)$ inflation. $\mathrm{CO}_{2}$ embolism is a rare reported complication from EVH. If the amount of $\mathrm{CO}_{2}$ embolized is large, the situation can become be critical. ${ }^{1}$ Here, we present an educational case that highlights the lifethreatening complication caused by $\mathrm{EVH}, \mathrm{CO}_{2}$ embolus, which was treated successfully. The accompanying transesophageal echocardiogram (TEE) images describe the event process, showing the path of $\mathrm{CO}_{2}$ bubbles from the right heart to left heart through a patent foramen ovale (PFO).

A 74-year-old woman presented for CABG following an anginal episode with subsequent coronary catherization that showed multivessel coronary artery disease. The EVH procedure proceeded in the usual fashion, using VASOVIEW HEMOPRO 2 (Maquet, Wayne, NJ) in closed tunnel technique with $\mathrm{CO}_{2}$ insufflation pressures of 10 to $12 \mathrm{~mm} \mathrm{Hg}$ and flow of $3 \mathrm{~L} / \mathrm{min}$, until EVH reached the high thigh saphenous vein, at which point sudden-onset hypotension and hypoxemia was noted. During resuscitation, TEE was performed, showing a dilated heart with a large number of bubbles entering the right side of the heart (Figure 1). EVH $\mathrm{CO}_{2}$ insufflation was immediately stopped at this point. The right internal jugular vein introducer skin

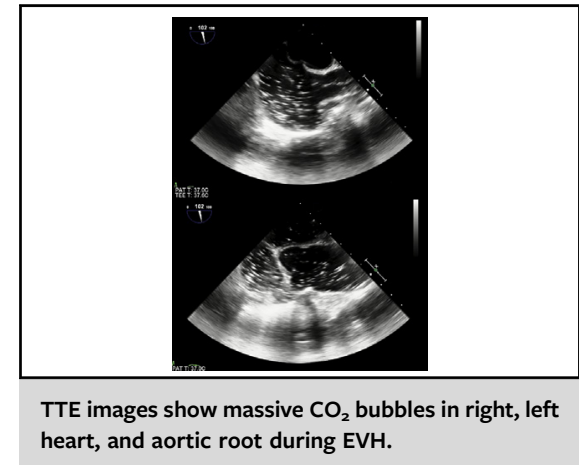

\begin{abstract}
CENTRAL MESSAGE
EVH is a safe, standard procedure that can cause critical complications. TEE allows early detection of critical conditions.
\end{abstract}

See Commentaries on pages 186 and 188. insertion site was assessed, and no skin integrity issues or stigmata of air entrainment were noted at the insertion site. In addition, none of the stopcocks on the central line were open to air. The bubbles were also seen crossing over to the left atrium via a PFO on TEE (Video 1). The stream of bubbles can be seen entering the aortic root (Video 2), and it is presumed the bubbles caused an air lock to the right ventricle, which increased right atrial pressure resulting in the right-to-left shunt (Figure 1).

The patient became bradycardic. Systemic heparin was given. Internal cardiac massage was performed (Video 3). Cardiopulmonary bypass (CPB) was initiated. Bi-caval venous cannulation was performed because of the $\mathrm{PFO}$ with associated right-to-left shunt. $\mathrm{EVH} \mathrm{CO} 2$ insufflation was resumed and a large amount of bubbles was noted to be entering the vacuum-assisted CPB venous drainage via the inferior vena cava (IVC) cannula (Video 4). The IVC was snared to prevent further introduction of bubbles into systemic circulation. Completion of EVH and cessation of $\mathrm{CO}_{2}$ insufflation stopped the drainage of bubbles into the IVC cannula. The surgery continued, cardioplegia was administered, and subsequently the team performed PFO closure and 2-vessel CABG. The vein harvest site had a moderate amount of venous bleeding that required a 


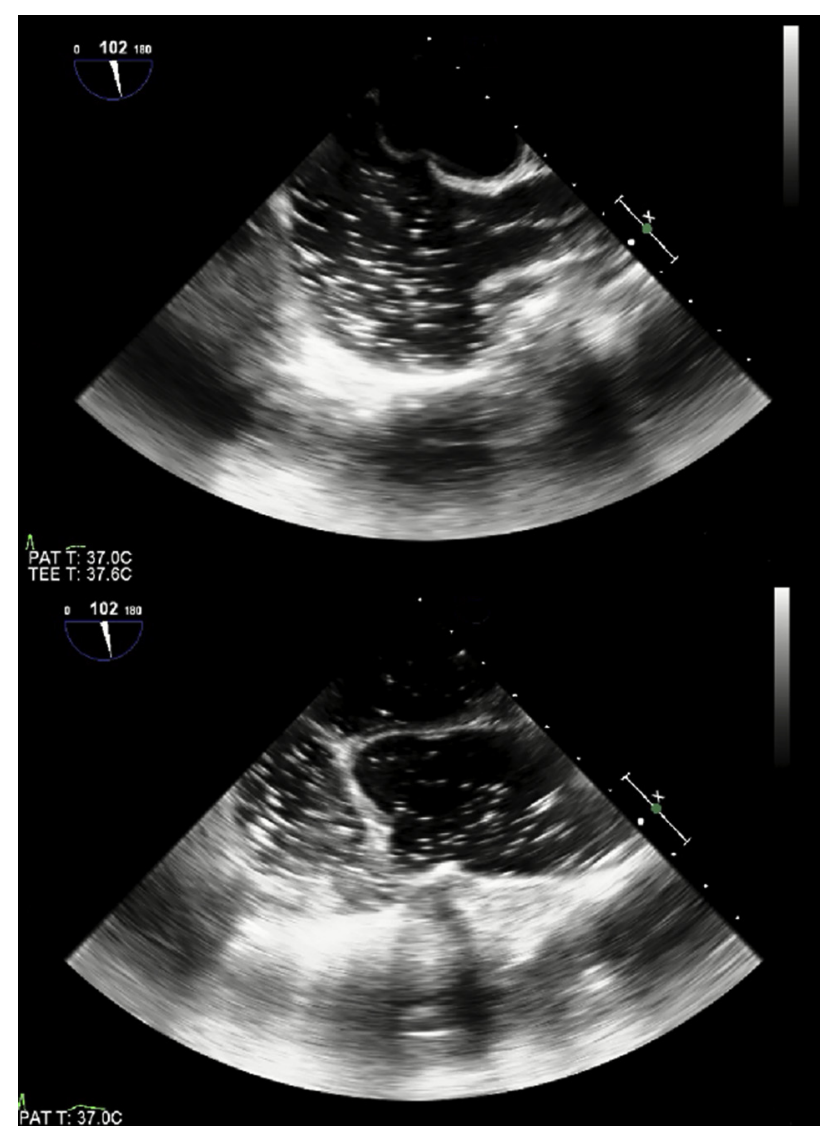

FIGURE 1. Top, TEE bi-caval view of right heart distension and which $\mathrm{CO}_{2}$ bubbles can be seen throughout. Bottom, TEE still image of $\mathrm{CO}_{2}$ in the aortic root, which indicates that there has been transmission of $\mathrm{CO}_{2}$ to the left heart and possible embolization of $\mathrm{CO}_{2}$ into the coronary arteries. TEE, Transesophageal echocardiogram; $\mathrm{CO}_{2}$, carbon dioxide.

compression wrapping during the case. The patient required milrinone and epinephrine for inotropic support, with adjunctive epoprostenol therapy for right heart dysfunction. The patient initially was brought out of the operating room

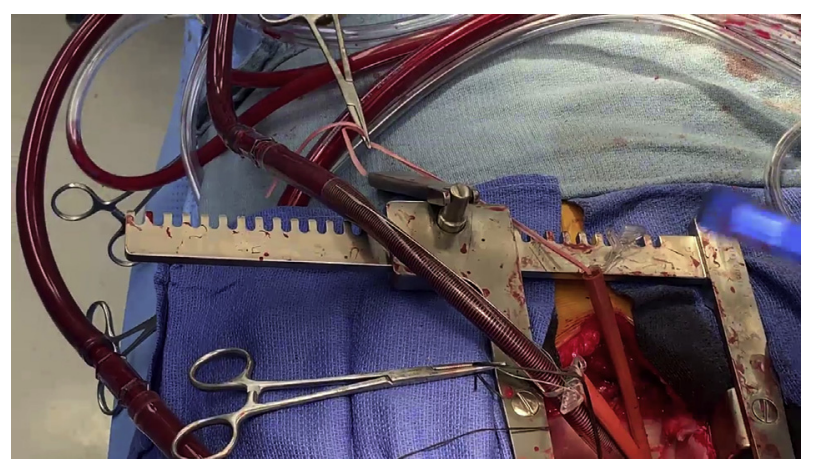

VIDEO 1. Transesophageal echocardiogram (TEE) film showing a distended right atrium with abundant carbon dioxide bubbles. The bubbles can be seen crossing a patent foramen ovale (PFO) in the upper portion of the image. Video available at: https://www.jtcvs.org/article/S26662507(20)30097-3/fulltext.

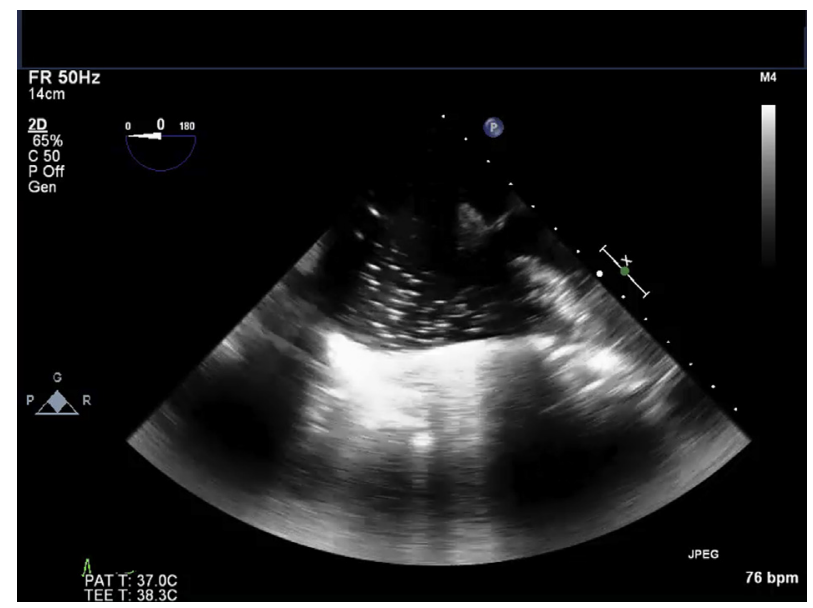

VIDEO 2. Transesophageal echocardiogram (TEE) film of carbon dioxide bubbles entering the aortic root, with assumed passing of the bubbles to the coronary arteries. Bubbles can additional be seen in both chambers of the left heart. Video available at: https://www.jtcvs.org/article/S26662507(20)30097-3/fulltext.

in open chest status. The right heart function recovered to normal and the sternum was closed on postoperative day 2. The patient was discharged on postoperative day 7 with intact neurologic status. The patient provided informed consent for the publication of the study data.

\section{COMMENT}

EVH is a safe, widely used method for vein harvesting that has largely replaced open vein harvesting, as EVH produces less postoperative pain and shorter duration of hospital stay. ${ }^{1}$ Complications of EVH include seroma/hematoma

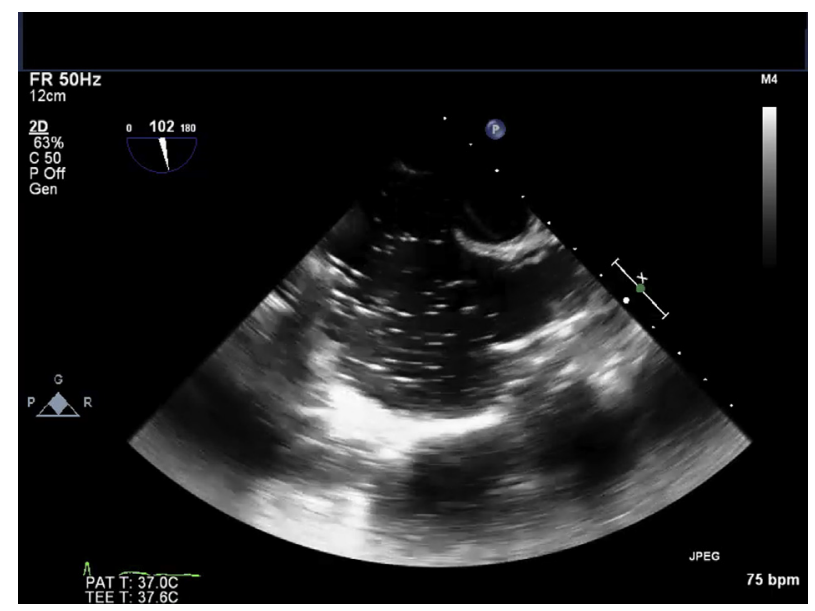

VIDEO 3. Transesophageal echocardiogram (TEE) film of the hypokinetic right heart being resuscitated with internal cardiac massage. The hands of the resuscitating physician can be seen at the inferior edge of the heart and carbon dioxide bubbles can be seen in both chambers of the right heart. Video available at: https://www.jtcvs.org/article/S26662507(20)30097-3/fulltext. 


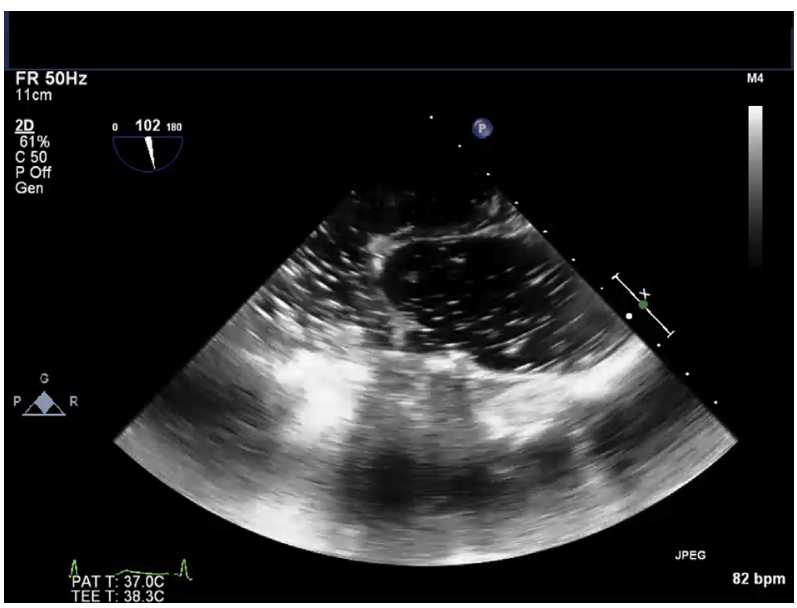

VIDEO 4. Massive amounts of carbon dioxide seen entering the cardiopulmonary bypass venous drainage via the IVC cannula. Demonstrating that there is introduction of carbon dioxide into the venous system during insufflation from endoscopic saphenous vein harvest (EVH). Video available at: https://www.jtcvs.org/article/S2666-2507(20)30097-3/fulltext.

formation, abscess collection, $\mathrm{CO}_{2}$ embolism, and erythema or cellulitis of the incision site. Erythema has the greatest incidence, in $3.8 \%$ of EVH procedures. ${ }^{2} \mathrm{CO}_{2} \mathrm{em}-$ bolism has an incidence that is inversely proportional to severity of symptoms, with venous embolism occurring in $17.1 \%$ of $\mathrm{EVH}$ and massive $\mathrm{CO}_{2}$ embolism, such as in our report, with an incidence of $0.5 \%{ }^{3}$ (Table 1). This incidence may be an underestimate, as most patients are asymptomatic or minimally symptomatic, and the minority of patients, particularly those with a PFO, are more susceptible to the life-threatening complications as presented here. ${ }^{4}$

Although $\mathrm{CO}_{2}$ embolism is a rare event during $\mathrm{EVH}$, its potential consequences can be devastating. In this case, cardiopulmonary resuscitation via internal cardiac massage was required due to likely air lock in the right heart that caused right ventricular dysfunction and dilation with high filling pressure, creating a right-to-left shunt through an existing PFO with subsequent coronary artery $\mathrm{CO}_{2}$ embolization. Cardiac arrest from EVH was reported in the past; however, real-time echocardiographic imaging has not yet been reported. ${ }^{1}$ Our TEE videos show the
TABLE 1. Recent literature

\begin{tabular}{cccccc}
\hline & \multicolumn{5}{c}{ Insufflation } \\
Study & Year & Sex & $\mathbf{y}$ & $\begin{array}{c}\text { pressure, } \\
\text { mm Hg }\end{array}$ & Observations \\
\hline $\begin{array}{c}\text { Fan } \\
\text { et al }\end{array}$ & 2012 & $\mathrm{~F}$ & 55 & 14 & $\begin{array}{c}\text { Rise of } \mathrm{ETCO}_{2} \text {, pulmonary } \\
\text { hypertension, cardiogenic } \\
\text { shock }\end{array}$ \\
$\begin{array}{c}\text { Strauss } \\
\text { et al }\end{array}$ & 2016 & $\mathrm{M}$ & 77 & 14 & $\begin{array}{c}\text { Auscultation of mill-wheel } \\
\text { murmur, TEE visualization }\end{array}$ \\
\hline ETCO $_{2}$, End-tidal carbon dioxide; $T E E$, transesophageal echocardiogram.
\end{tabular}

massive right ventricular embolism entering the left heart through the PFO. Traditionally, end-tidal $\mathrm{CO}_{2}$ concentration has been used to monitor for $\mathrm{CO}_{2}$ embolus, but with the availability of TEE in the operating room setting, endtidal monitoring is being replaced in favor of TEE. ${ }^{5}$ This case highlights the importance of TEE in diagnosing $\mathrm{CO}_{2}$ embolus in a timely manner, thereby allowing the operating room team to rapidly initiate resuscitation. The rapid cessation of $\mathrm{CO}_{2}$ insufflation and initiation of CPB allowed for a positive outcome.

We hope this case report with TEE images demonstrates this potentially critical complication from EVH and can assist in the rapid diagnosis and treatment of $\mathrm{CO}_{2}$ embolism.

\section{References}

1. Banks TA, Manetta F, Glick M, Graver L. Carbon dioxide embolism during minimally invasive vein harvesting. Ann Thorac Surg. 2002;73:296-7.

2. Felisky CD, Paull DL, Hill ME, Hall RA, Ditkoff M, Campbell WG, et al. Endoscopic greater saphenous vein harvesting reduces the morbidity of coronary artery bypass surgery. Am J Surg. 2002;183:576-9.

3. Fan L, Denisco D, Knorz DL, Mapes RM, Nader ND. A case report of a carbon dioxide embolism caused by endoscopic vein harvesting during cardiac surgery—a case report. Korean J Anesthesiol. 2012;63:161.

4. Suarez-Pierre A, Terasaki Y, Magruder JT, Kapoor A, Grant MC, Lawton JS. Complications of $\mathrm{CO}_{2}$ insufflation during endoscopic vein harvesting. J Card Surg. 2017;32:783-9.

5. Chavanon O, Tremblay I, Delay D, Bouveret A, Blain R, Perrault LP. Carbon dioxide embolism during endoscopic saphenectomy for coronary artery bypass surgery. J Thorac Cardiovasc Surg. 1999;18:557-8.

6. Strauss E, Taylor B, Mazzeffi M, Tanaka K, Odonkor P. The auscultation of a carbon dioxide embolization event during endoscopic vein harvest. Case Rep Anesthesiol. 2016;2016:6947679. 